\title{
EFFECT OF EXPERIMENTAL SALT DEPLETION AND ALDOSTERONE LOAD ON SODIUM AND CHLORIDE CONCENTRATION IN THE SWEAT OF PATIENTS WITH CYSTIC FIBROSIS OF THE PANCREAS AND OF NORMAL CHILDREN* ${ }^{*}$
}

\author{
BY \\ P. SIEGENTHALER, J. De HALlER, R. De HALlER, A. HAMPAÏ and A. F. MULLER \\ From Policlinique Universitaire de Médecine, Clinique Universitaire de Pédiatrie et Laboratoire \\ de Physiopathologie Clinique, Hôpital Cantonal, Genève, Switzerland
}

(RECEIVED FOR PUBLICATION AUGUST 21, 1963)

Aldosterone plays an important part in the regulation of the extracellular volume. It is known today that this corticosteroid influences not only the tubular reabsorption of sodium in the kidneys, but also intervenes in the sodium elimination mechanism of the sweat glands (Siegenthaler, de Haller, Veyrat and Muller, 1962).

The study of the renal and extrarenal effect of aldosterone is best accomplished by experimental salt depletion, produced by a strict salt-free diet. Fig. 1 shows the variations of some parameters such as weight, natriuresis, sodium and chloride concentration in sweat, and urinary aldosterone, as observed in the course of saline depletion produced in a young healthy adult. The salt loss is precipitated by administration of a saliuretic substance (chlorthalidone) on the first and second day of the diet. Under these conditions the weight, as well as the urinary sodium excretion, decrease rapidly and progressively to a minimum on the fourth day. At the same time there is an important fall in the sweat sodium and chloride concentration, expressed in $\mathrm{mEq}$ per litre. As for the urinary aldosterone it increases noticeably reaching very high levels at the end of the test.

\section{Method}

In our experiments, perspiration was provoked by iontophoresis with $0 \cdot 2 \%$ pilocarpine nitrate on the forearms of children and on the abdominal wall of small infants (Gibson and Cooke, 1959). The electrolytes were determined directly in the sweat by micromethod. Sodium was measured by flame photometry and chloride according to Schales and Schales (1941),

\footnotetext{
* Paper presented at the annual meeting of the Swiss Society of Paediatrics, Geneva, June 7-9, 1963.

$\dagger$ Study supported by a grant from the National Swiss Foundation for Scientific Research.
}

using the Beckman-Spinco ultra-analytic equipment. Urinary aldosterone was determined by a double microisotope dilution method (Kliman and Peterson, 1960).

\section{Results}

The variations in sodium in the urine and sweat during the strict salt-free diet are the result of an increased production of aldosterone. This is shown by inhibiting this effect through administration of an anti-aldosterone during the course of the salt-free diet (Fig. 1). Steroidal spirolactones were used, which block the renal sodium retention effect of aldosterone by competitive inhibition. In this second experiment, the subject receives, during the salt-free diet period, 1,200 to $1,800 \mathrm{mg}$. per day of spirolactone. Again there is a marked increase of urinary aldosterone as a consequence of salt depletion. On the other hand the natriuresis remains relatively high this time, and the concentration of sodium and chloride in the sweat does not fall because of the aldosterone inhibition caused by the spirolactones. The effect of the anti-aldosterone is thus observed in the kidneys as well as in the sweat glands. Furthermore, these results show the existence of an extrarenal action of aldosterone.

When aldosterone is lacking, the organism loses its ability of adaptation to a state of salt depletion. This can be demonstrated by submitting a patient with Addison's disease to a salt-free diet (Fig. 2). The salt loss is again accentuated by administration of a saliuretic substance in the same manner as in the previous test. The weight loss is very great in three days. Contrary to what is seen in a normal subject under the same conditions, natriuresis remains fairly high until the end of the test, and sweat sodium and chloride concentrations do not 


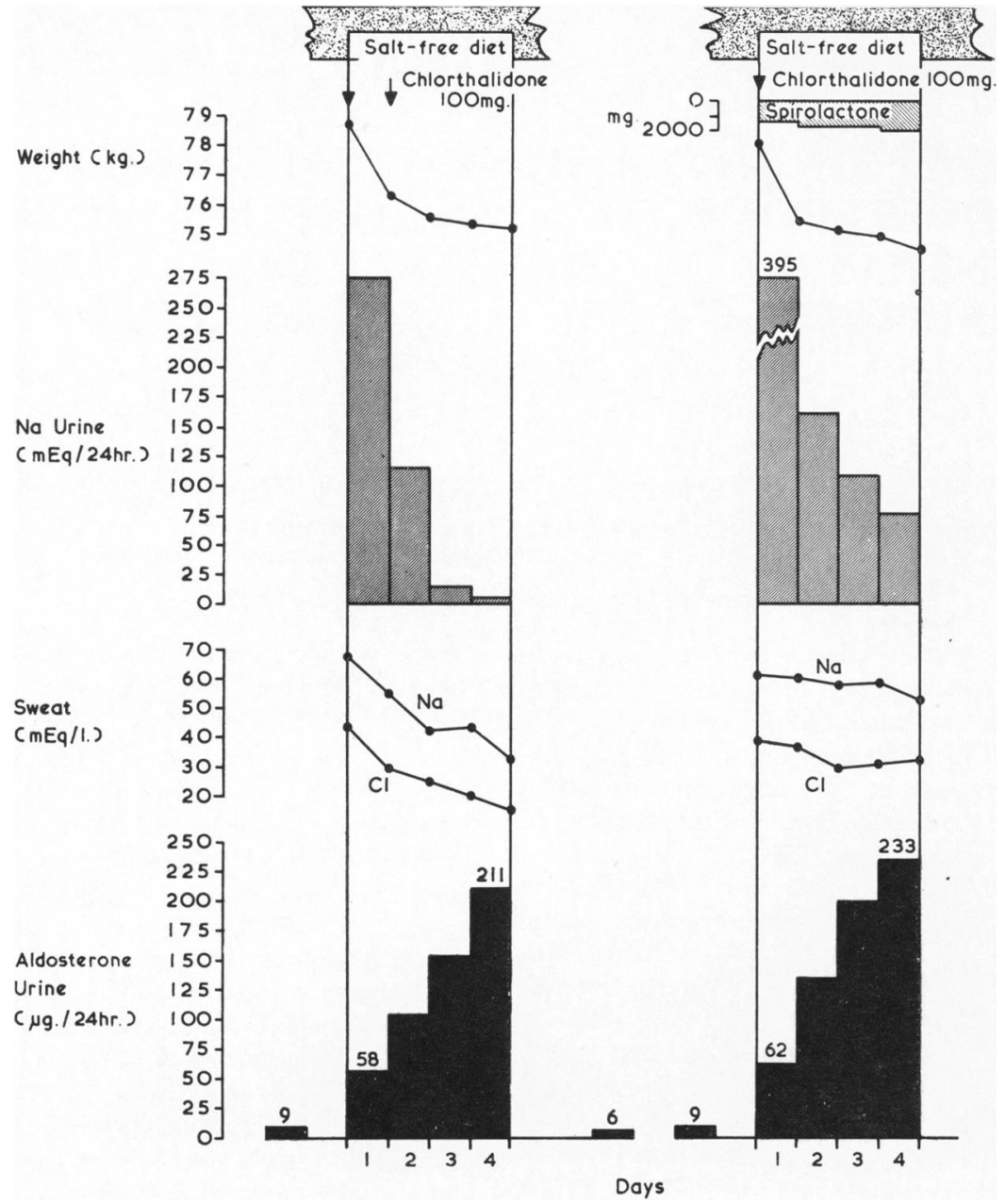

FIG. 1.-Variations of urinary sodium, sweat sodium and chloride concentration and urinary aldosterone during salt depletion in a young adult. The effect of aldosterone on urinary and sweat sodium is inhibited by simultaneous administration of an anti-aldosterone (spirolactone).

diminish. In Addison's disease salt loss is not tolerated as aldosterone secretion is deficient. This is shown by the very low quantity of this hormone found in the urine at the end of the present experiment: only $0.5 \mu \mathrm{g}$., while 150 to $200 \mu \mathrm{g}$. or more are found in a normal subject undergoing the same salt depletion test (Siegenthaler et al., 1962).

It has been well established that the excretion of sodium and of chloride in sweat is increased in cystic fibrosis of the pancreas (di Sant' Agnese and Vidaurreta, 1960). This sweat anomaly is constant and persists even if salt is restricted in the diet. A sodium concentration above $80 \mathrm{mEq}$ per litre and a chloride concentration higher than $60 \mathrm{mEq}$ per litre in a child suffering from steatorrhoea, whether or not associated with respiratory disorders, confirms the diagnosis of fibrocystic disease.

Knowing now the important part played by aldosterone in the elimination of salt through the kidneys as well as through the sweat glands one could question whether, in cystic fibrosis of the pancreas, the excessive loss of sodium and chloride in the sweat might be due to a possible defect in the production of aldosterone. In order to answer this question, the elimination of aldosterone in the urine was determined in four children aged 6 months to 16 years suffering from cystic fibrosis of the pancreas, whose sweat sodium was pathological (Table). The results obtained were compared with those found in five healthy children aged 6 weeks to 7 months. 
TABLE

ALDOSTERONE IN URINE OF CHILDREN WITH CYSTIC FIBROSIS OF THE PANCREAS AND OF NORMAL CHILDREN

\begin{tabular}{|c|c|c|c|c|c|c|}
\hline Cases & & & Age and Sex & $\begin{array}{l}\text { Na Sweat } \\
(\mathrm{mEq} / \mathrm{l} .)\end{array}$ & $\begin{array}{c}\mathrm{Na} \text { Urine } \\
\text { (mEq/24 hrs.) }\end{array}$ & $\begin{array}{c}\text { Urinary Aldosterone } \\
\text { ( } \mu \mathrm{g} . / 24 \mathrm{hrs} .)\end{array}$ \\
\hline $\begin{array}{c}\text { Children with CFP. } \\
\text { Ch.M. } \\
\text { L.D. } \quad \cdots \\
\text { P.S. } \quad \cdots \\
\text { R.P. } \quad \cdots\end{array}$ & $\begin{array}{l}\cdots \\
\cdots \\
\cdots \\
\cdots\end{array}$ & $\begin{array}{l}\cdots \\
\cdots \\
\cdots \\
\cdots\end{array}$ & $\begin{array}{rll}6 \text { mths.; } & M \\
10 \text { mths.; } & M \\
14 \text { yrs.; } & F \\
16 \text { yrs.; } & M\end{array}$ & $\begin{array}{r}106 \\
98 \\
118 \\
122\end{array}$ & $\begin{array}{l}0 \cdot 5 \\
57 \\
75\end{array}$ & $\begin{array}{r}17 \cdot 5 \\
21 \cdot 6 \\
7 \cdot 6 \\
13 \cdot 4\end{array}$ \\
\hline 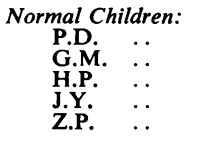 & $\begin{array}{l}\cdots \\
\cdots \\
\cdots \\
\cdots\end{array}$ & $\begin{array}{l}\cdots \\
\cdots \\
\cdots \\
\cdots\end{array}$ & $\begin{array}{ll}6 \text { wks.; } & M \\
6 \text { wks.; } & M \\
3 \text { mths.; } & M \\
3 \text { mths.; } & M \\
7 \text { mths.; } & M\end{array}$ & $\frac{40}{\overline{20}}$ & $\begin{array}{l}2 \cdot 9 \\
13 \\
27 \\
5 \cdot 5 \\
17\end{array}$ & $\begin{array}{l}6 \cdot 5 \\
1 \cdot 0 \\
3 \cdot 1 \\
5 \cdot 7 \\
7 \cdot 8\end{array}$ \\
\hline
\end{tabular}

Aldosterone is present in normal amount in the urines of children suffering from cystic fibrosis of the pancreas; in small babies urinary output is even increased. The stimulation of aldosterone production is most probably related to a certain degree of salt depletion as a result of an excessive loss of $\mathrm{NaCl}$ by perspiration in these small children with a relatively large skin surface. These results indicate that the rise of sweat sodium in patients with fibrocystic disease is not related to a lack of endogenous aldosterone.

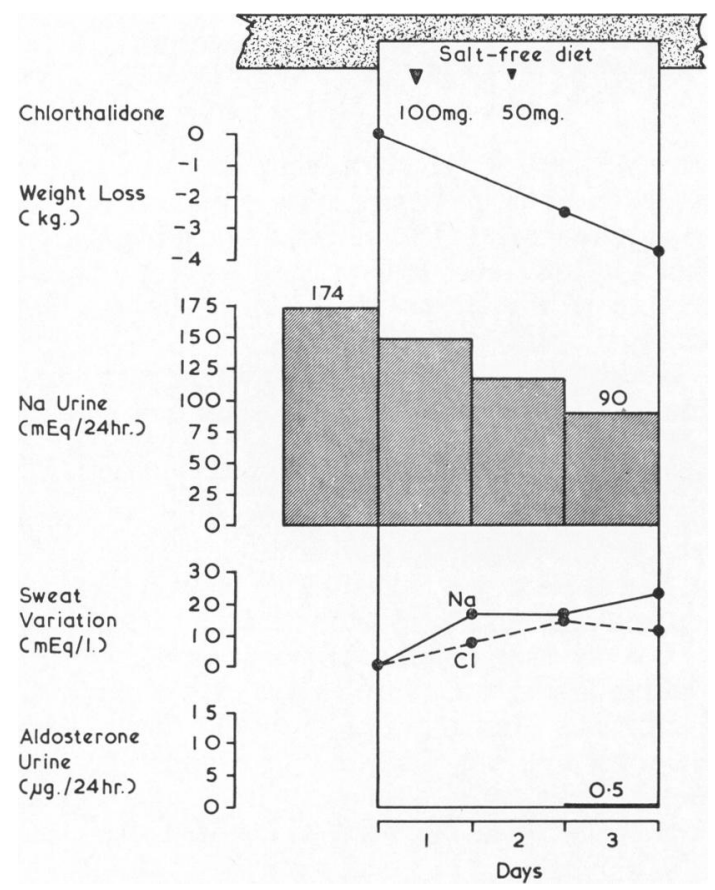

Fig. 2.-Urinary and sweat sodium excretion remain high during salt deprivation in Addison's disease as no aldosterone is produced by the adrenal glands.
This fact is further illustrated by successive determinations of urinary aldosterone in a young girl of 14 years, who was suffering from cystic fibrosis of the pancreas. She was subjected in the usual manner to a salt-free diet for four days (Fig. 3), and

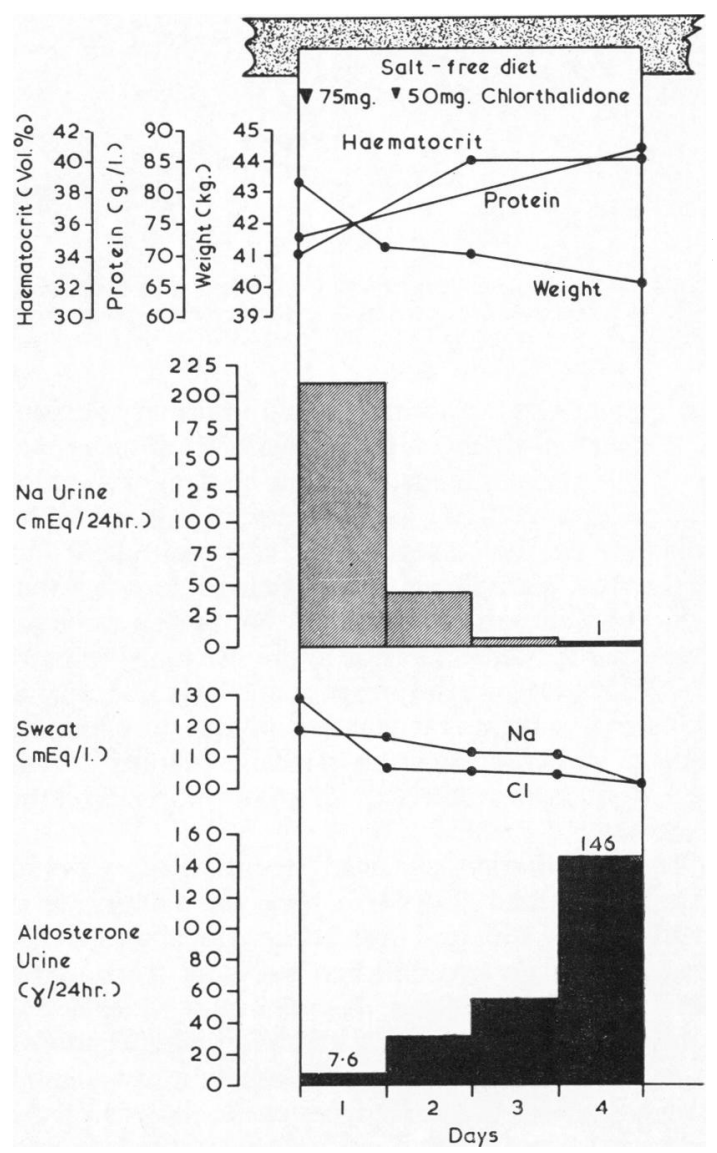

FIG. 3.-Salt depletion in a child of 14 years with cystic fibrosis of the pancreas is followed by a normal aldosterone production. Nevertheless, sweat sodium and chloride concentrations remain high. 


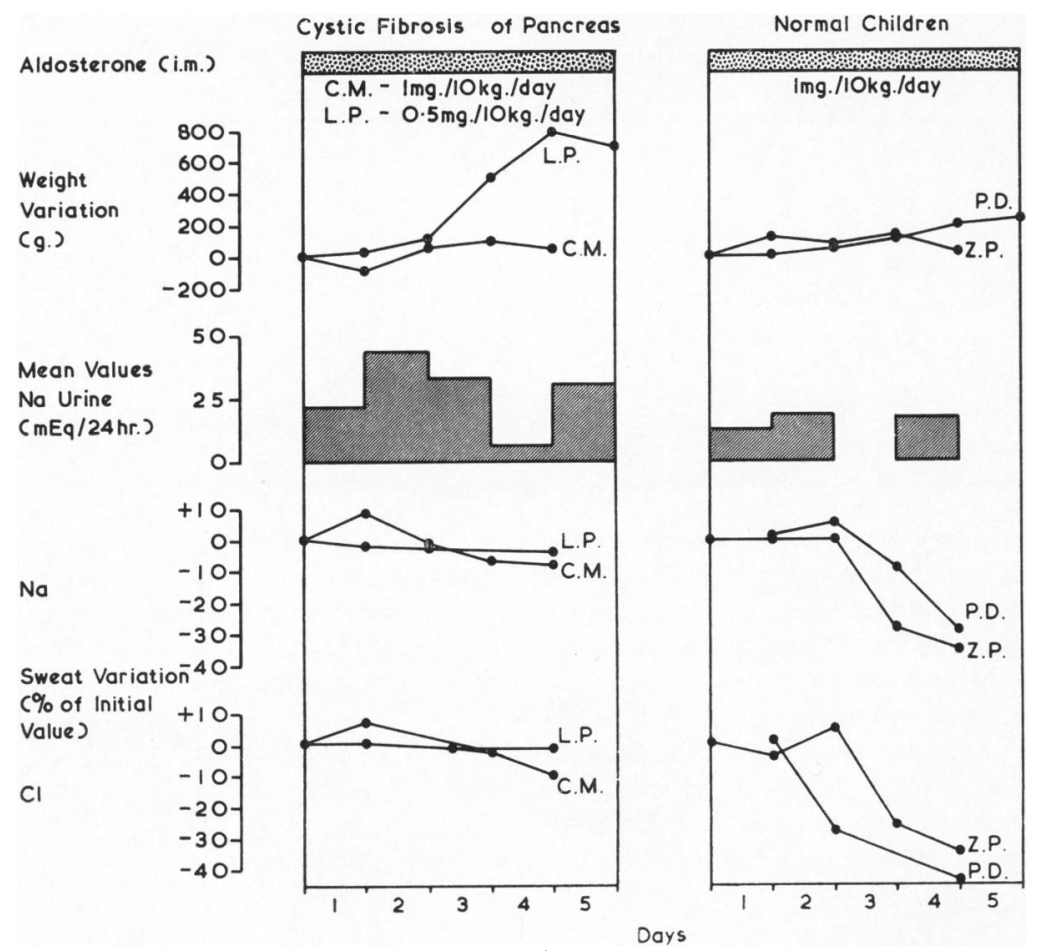

Fig. 4.-Aldosterone load in children with cystic fibrosis of the pancreas and in normal children. There is no decrease of sweat sodium and chloride concentration in cystic fibrosis of the pancreas. In the controls a striking fall of these electrolytes is observed.

she lost weight. The striking fall in urinary sodium is the consequence of the increase in aldosterone, as in a normal subject. In this patient, the aldosterone production is perfectly adequate. The response of the adrenal glands to salt depletion is thus comparable to that observed in a normal subject in the same condition. On the other hand, the sodium and the chloride in the sweat are scarcely modified. Despite the presence of a large quantity of aldosterone, the sweat glands continue to eliminate sodium and chloride in an excessive manner. This behaviour is characteristic of cystic fibrosis of the pancreas.

This peculiarity can also be revealed with an aldosterone load (Fig. 4), which was administered at a dose of 0.5 to $1 \mathrm{mg} . / 10 \mathrm{~kg}$. body weight for several days to two children suffering from cystic fibrosis of the pancreas, 6 weeks and 8 years old respectively. Two healthy children under 7 months were used as controls. Once again it was noted that in children suffering from cystic fibrosis of the pancreas, sweat sodium and chloride concentration were scarcely modified despite the administration of a very high dose of aldosterone. In contrast, the two normal children showed a substantial reduction in the concentration of these two electrolytes in the sweat. This high dose of aldosterone does not cause much fall in urinary sodium excretion because of the escape phenomenon (Relman and Schwartz, 1952).

In a child suffering from digestive and respiratory disorders the discovery of a high sodium and chloride concentration in the sweat makes the diagnosis of cystic fibrosis of the pancreas certain. However, the dynamic tests described, in the form of a strict salt-free diet or an aldosterone load, may be useful in ascertaining the diagnosis in adolescents and adults. Indeed, after puberty, it is not uncommon to find occasional high sodium or chloride concentrations in the sweat, which are of no particular significance. But the persistence of high levels in the course of salt depletion or aldosterone load constitutes a valid argument in favour of the diagnosis of cystic fibrosis of the pancreas.

\section{Summary}

Sodium and chloride excretion in sweat is partially controlled by aldosterone. If this corticosteroid is 
lacking, as in Addison's disease, there is excessive salt loss in sweat. On the other hand, abnormally high sweat sodium and chloride concentrations in children suffering from cystic fibrosis of the pancreas are not related to a deficient production of endogenous aldosterone. This can be demonstrated by experimental salt depletion during which a very high urinary aldosterone output is found, and by the determination of urinary aldosterone in children with cystic fibrosis of the pancreas. In this disease sodium and chloride excretion in sweat remains pathological $(\mathrm{Na}>80 \mathrm{mEq}$ per litre and $\mathrm{Cl}>60$ $\mathrm{mEq}$ per litre) even during salt depletion or aldosterone load. In normal persons these electrolytes show a striking decrease in the same condition. This observation can be used for the diagnosis of cystic fibrosis of the pancreas in adolescents and adults where occasional high sodium and chloride levels without any significance are found.

\section{REFERENCES}

di Sant'Agnese, P. A. and Vidaurreta, A. M. (1960). Cystic fibrosis of the pancreas. J. Amer. med. Ass., 172, 2065.

Gibson, L. E. and Cooke, R. E. (1959). A test for concentration of electrolytes in sweat in cystic fibrosis of the pancreas utilizing pilocarpine by iontophoresis. Pediatrics, 23, 545.

Kliman, B. and Peterson, R. E. (1960). Double isotope derivative assay of aldosterone in biological extracts. J. biol. Chem. $235,1639$.

Relman, A. S. and Schwartz, W. B. (1952). The effect of DOCA on electrolyte balance in normal man and its relation to sodium chloride intake. Yale J. Biol. Med., 24, 540.

Schales, O. and Schales, S. S. (1941). A simple and accurate method for the determination of chloride in biological fluids. $J$. biol. Chem., 140, 879 .

Siegenthaler, P., de Haller, R., Veyrat, R. and Muller, A. F. (1962) Influence d'un inhibiteur et d'un antagoniste de l'aldostérone Influence d'un inhibiteur et d'un antagoniste de l'aldostérone
sur la concentration du sodium sudoral. Effet extra-rénal des spirolactones. Helv. med. Acta, 29, 550. 